\title{
Evaluation and management of toppling failures at the McArthur River Mine, Northern Territory
}

\author{
CEV Heaven Glencore, Australia \\ DBM Bran Glencore, Australia \\ WA Norrie Glencore, Australia
}

\begin{abstract}
This paper describes the most recent multi-bench failure within the northwest wall of the McArthur River Mine. Discussion will include events leading up to the toppling style of failure and focuses on: (i) the role of geology in controlling the onset of instability, (ii) the role of rainfall and transient pore pressure for triggering the failure (iii) the monitoring systems that were in place to provide early warning of the instability and (iv) the remediation plan for the wall.

The McArthur River Mine is located approximately $700 \mathrm{~km}$ southeast of Darwin, in the Northern Territory of Australia. The open pit is being developed in stages, with current dimensions of approximately $1 \mathrm{~km}$ wide by $1.6 \mathrm{~km}$ long, and with a current depth of $200 \mathrm{~m}$. Since January 2010 there have been four instances of multi-bench instability along the northwestern pit wall, the largest occurring in December 2015. This eventually led to wall failures, forcing the closure of access to the area. Personnel and equipment damage were eliminated due to early detection from monitoring equipment onsite. Back-analysis and video footage from one of the failure events, identified toppling as a mechanism, with transient pore pressure as a result of rainfall immediately prior to failure.
\end{abstract}

Keywords: failure, case study, toppling

\section{$1 \quad$ McArthur River Mine}

Glencore owned McArthur River Mine (MRM), situated approximately $700 \mathrm{~km}$ southeast of Darwin in the Northern Territory of Australia, is one of the world's largest lead and zinc mines. Initially an underground mining operation, the mine has since been converted to an open cut mine and hosts a pit with dimensions of $1.6 \mathrm{~km}$ by $1.0 \mathrm{~km}$ with and current depth of $200 \mathrm{~m}$.

Since January 2010, there have been four toppling failures, shown in Figure 1, along the western wall termed the 'Footwall Quarry' (FWQ). The largest of the toppling failures occurred in December 2015, an inter-ramp failure with an estimated failure volume of $355,000 \mathrm{~m}^{3}$. The second largest occurred in March 2019 with an estimated failure volume of approximately $36,000 \mathrm{~m}^{3}$. All of the failures occurred after heavy rainfall events, two of which occurred during a cyclone (January 2010, Cyclone Olga and March 2019, Cyclone Trevor). The combination of weaker rock mass, unfavourable bedding orientation, and water infiltration during the wet season, the potential for toppling has been, and will remain, a continuous geotechnical risk for the MRM.

Although mine production and tonnes were significantly affected during and after the failures, the potential for equipment damage and fatality were avoided with the aid of reliable slope monitoring equipment and analysis tools. To help better manage potential slope instability along the FWQ wall, the four historic toppling failures were back analysed and various consulting groups were engaged to help better understand the slope performance of the FWQ. This paper will detail:

- Role of the geology in controlling the onset of instability.

- Role of rainfall and transient pore pressure for triggering the failure. 
- Monitoring systems that were implemented to provide early warning of the instability.

- Remediation plan for the wall.

- Lessons learnt for continuous improvement.

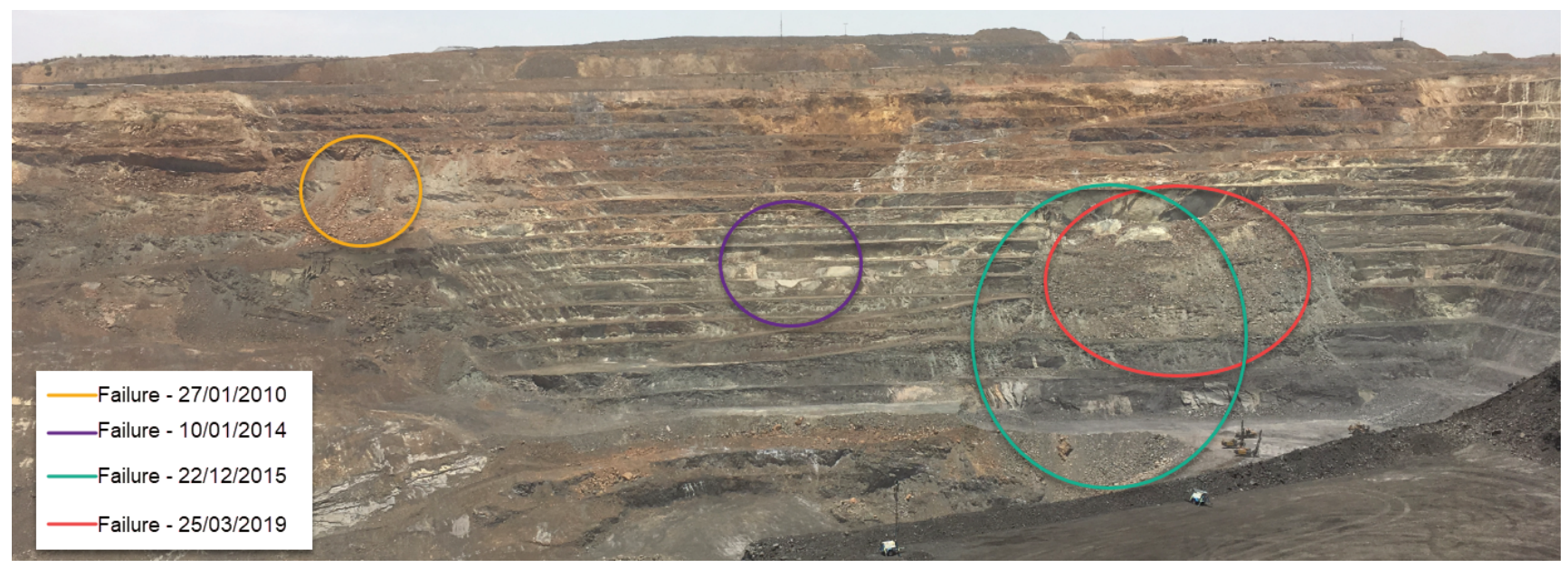

Figure 1 Footwall Quarry along the northwestern wall of the pit highlighting the areas subjected to previous failures (October 2019)

\section{Geology}

The MRM deposit is a strata-bound sedimentary deposit with varying beds consisting of dolomitic, bituminous, pyritic shales and breccias with interbedded tuffaceous beds. The depression of the MRM basin caused faulting and jointing of the shales which were later infilled by dolomitic or carbonate hydrothermal fluids, thus altering the original composition of the shale. There are two main fold zones that divide the pit, the lower fold zone along the eastern wall and the upper fold zone along the western margin in the FWQ. The upper fold zone within the FWQ consists of footwall shales, footwall dolomites and tuffaceous clay bands.

\subsection{Footwall shales}

The footwall shales comprise two shale rock types, the Lower Dolomitic Shale (LdH) and the W-Fold Shale (WFS) as shown in Figure 2. The LdH consists of interbedded pyritic shale, sedimentary turbidite breccia and consistent tuff bedding. Considered barren, the LdH is also made up of large nodular dolomitic concretions, which can clearly be identified in core samples by its rounded nature and light grey colour amongst the darker grey shale matrix.

Apart from the grey shale colour, the WFS shale exhibits two distinct colours which correspond to depositional type. The first has a high chlorite content and has a greenish tinge with a serpentinite texture, and the second has a high iron oxide content and which displays a bright pink colour. Both WFS units contain a high tuffaceous content and as a result, the rock type decays rapidly when exposed. This deterioration process reduces the rock into small flakes thus losing its textural integrity and rock mass strength. 

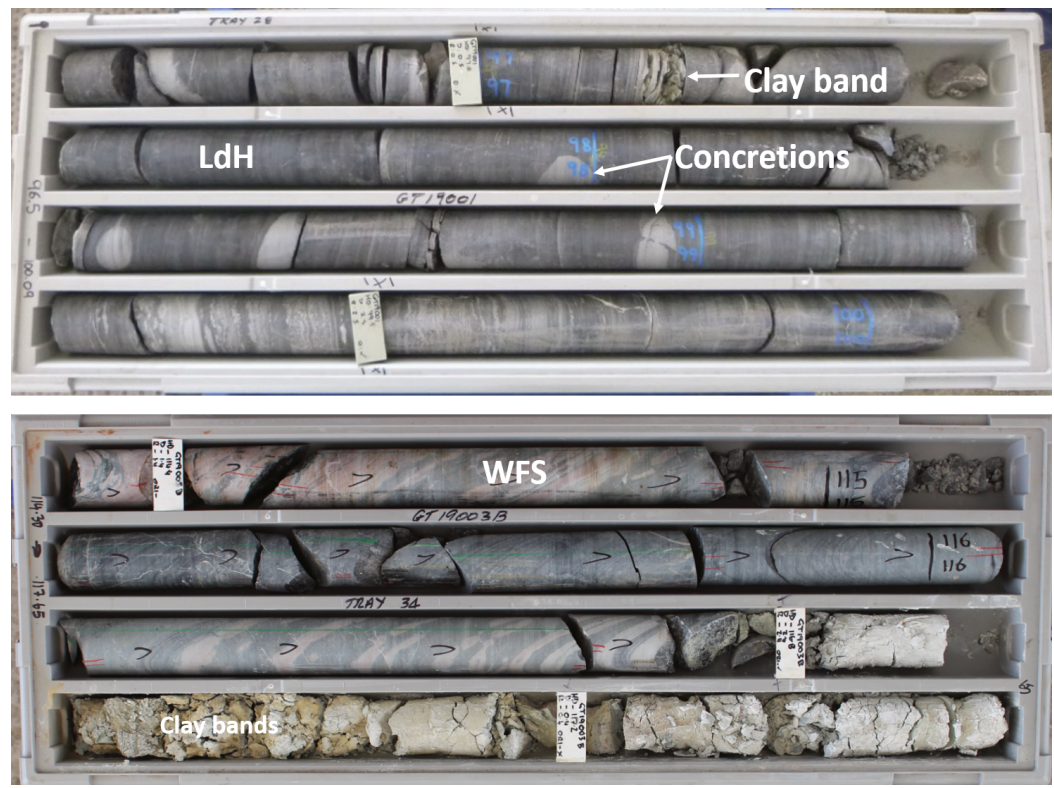

Figure 2 Lower dolomitic shale ( $\mathrm{LdH})$ consisting of interbedded shale (dark grey colour) with dolomitic concretions (light grey). W-Fold Shale (WFS) pink and grey with a green tinge. Clay bands are consistently interbedded throughout the Footwall Shale

\subsubsection{Footwall dolomites}

Behind the footwall shale layer in the FWQ wall is the Teena Dolomite (pmp). The contact between the WFS and pmp is gradational and hence proven to be difficult to distinguish. This can best be done through a comparison of the colour and hardness of the rock mass. The unaltered pmp rock strength situated further from the contact is strong with an estimated uniaxial compressive strength (UCS) of approximately $150 \mathrm{MPa}$. With the inclusion of clay bands however, the rock strength is significantly reduced.

\subsubsection{Tuffaceous clay bands}

Interbedded throughout the hanging wall to the footwall is the tuffaceous bedding also known as the clay bands. The clay bands are strata-bound and vary in thickness and spacing. Similar to the lower dolomitic and W-Fold shales, the clay bands deteriorate rapidly within a number of days. Due to the tuffaceous bands' low permeability, they act as a barrier for ground and surface water, thus increasing the pore pressure behind the FWQ wall. The clay bands are consistent within the FWQ wall at an average spacing of approximately 1-2 $m$ as shown in Figure 3.

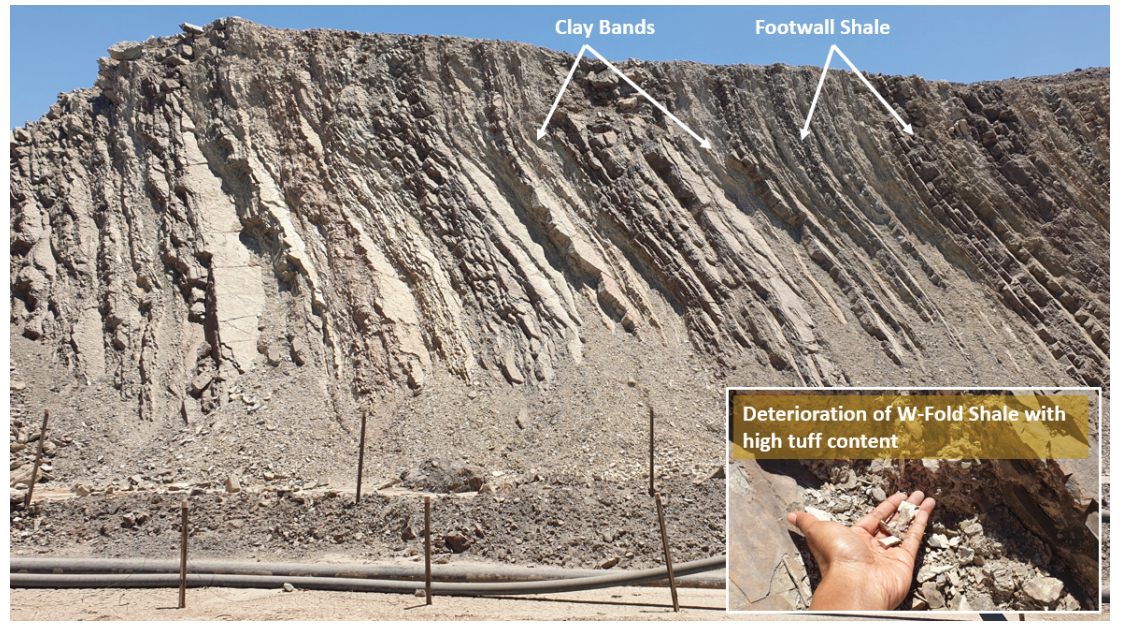

Figure 3 Exposure along the northwest wall showing interbedded footwall shales and clay/tuffaceous bands 


\subsection{Major structures}

The thin bedding planes in the footwall quarry are regularly spaced and strike near parallel to the slope face. Field mapping and borehole data show dips of $55^{\circ}$ to $85^{\circ}$ into the pit. However, as a result of folding in some areas the dip can vary along the same bedding plane. Two major faults, the Whelans, dipping East at approximately $85^{\circ}$, and Spanswick, dipping northeast at approximately $80^{\circ}$, are near parallel to these bedding planes, whilst the Goanna Fault, dipping north at approximately $85^{\circ}$, is perpendicular to bedding towards the northern corner of the FWQ wall as shown in Figure 4.

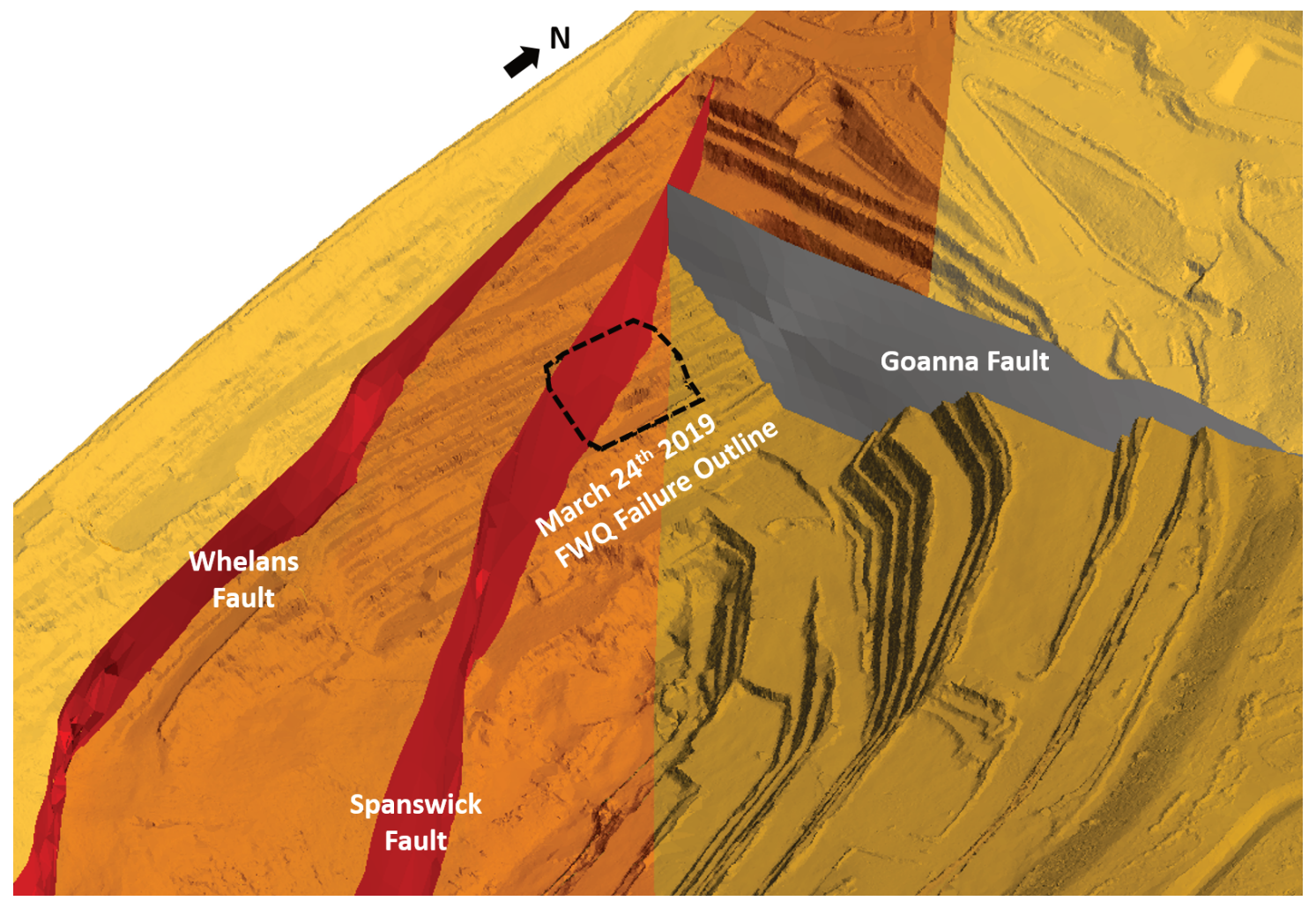

Figure 4 Plot showing major structures within the northwestern wall of the Footwall Quarry

\subsection{Engineering geology}

Figure 5 is a stereonet plot presenting major structures and bedding mapped in the FWQ as slopes have been exposed during mining. The dip and dip direction of the assessed major sets are bedding $78^{\circ} / 115^{\circ}$, joint set 1 (J1) $83^{\circ} / 120^{\circ}$ and joint set 2 (J2) $65^{\circ} / 030^{\circ}$. The steeply dipping bedding plane dipping parallel to the pit slope can be attributed to the instabilities in the FWQ.

Extensive mapping of exposed pit walls and borehole logging provided information for determining the rock mass properties, Table 1 summarises the rock mass property values used at MRM.

Table 1 Adopted material properties values by BFP Consultants for UDEC modelling and clay band characteristics

\begin{tabular}{lccccccc}
\hline Rock unit & $\begin{array}{c}\text { UCS } \\
\text { (MPa) }\end{array}$ & GSI & Q & $\begin{array}{c}\text { Cohesion } \\
\text { (MPa) }\end{array}$ & $\begin{array}{c}\text { Friction } \\
\text { angle } \\
\text { (deg.) }\end{array}$ & $\begin{array}{c}\text { Average } \\
\text { spacing of } \\
\text { clay bands }\end{array}$ & $\begin{array}{c}\text { Average } \\
\text { thickness of } \\
\text { clay bands }\end{array}$ \\
\hline W-fold shale & $83^{*}$ & 43 & 1.5 & $14^{*}$ & $45^{*}$ & 1.7 & 164 \\
Lower dolomite shale & 83 & 41 & 1.3 & 14 & 45 & 3.5 & 94 \\
Teena dolomite & $120^{*}$ & 51 & 3.2 & 36 & 38 & 2.9 & 93 \\
\hline
\end{tabular}

*Estimated values. UCS - uniaxial compressive strength; GSI - geological strength index. 


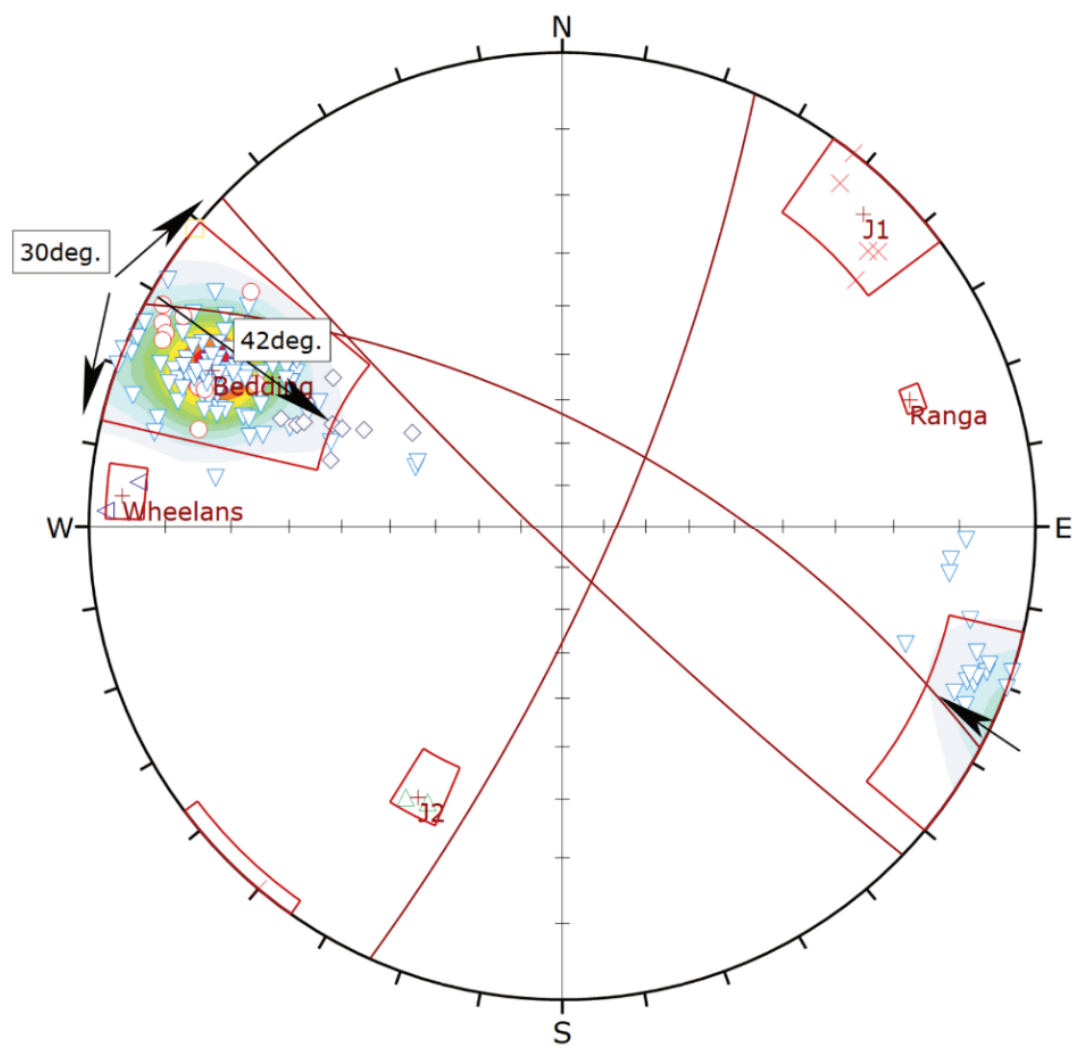

\begin{tabular}{|c|c|c|c|c|}
\hline Symbol & REVTYPE & & & Quantity \\
\hline$\diamond$ & Batter & & & 10 \\
\hline$x$ & j1 & & & 6 \\
\hline$\Delta$ & 32 & & & 2 \\
\hline+ & Ranga & & & 1 \\
\hline$\nabla$ & so & & & 130 \\
\hline$\square$ & so & & & 1 \\
\hline$\triangleleft$ & Whelans & & & 2 \\
\hline 0 & batter & & & 11 \\
\hline \multirow{11}{*}{\multicolumn{2}{|c|}{ Color }} & \multicolumn{3}{|c|}{ Density Concentrations } \\
\hline & & 0.00 & -4.80 & \\
\hline & & & - 9.60 & \\
\hline & & 9.60 & - $\quad 14.40$ & \\
\hline & & 14.40 & $\begin{array}{l}-\quad 19.20 \\
-12-1\end{array}$ & \\
\hline & & 19.20 & - $\quad 24.00$ & \\
\hline & & 24.00 & - $\quad 28.80$ & \\
\hline & & 28.80 & 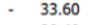 & \\
\hline & & 33.60 & - $\quad 38.40$ & \\
\hline & & 38.40 & - $\quad 43.20$ & \\
\hline & & 43.20 & $\begin{array}{r}-\quad 48.00 \\
\end{array}$ & \\
\hline \multicolumn{2}{|c|}{ Maximum Density } & \multicolumn{3}{|l|}{$47.10 \%$} \\
\hline \multicolumn{2}{|r|}{ Contour Data } & \multicolumn{3}{|c|}{ Pole Vectors } \\
\hline \multicolumn{2}{|c|}{ Contour Distribution } & \multicolumn{3}{|l|}{ Fisher } \\
\hline \multicolumn{2}{|c|}{ Counting Circle Size } & \multicolumn{3}{|l|}{$1.0 \%$} \\
\hline \multicolumn{2}{|r|}{ Plot Mode } & \multicolumn{3}{|c|}{ Pole Vectors } \\
\hline \multicolumn{2}{|r|}{ Vector Count } & \multicolumn{3}{|c|}{163 (163 Entries) } \\
\hline \multicolumn{2}{|r|}{ Hemisphere } & \multicolumn{3}{|l|}{ Lower } \\
\hline \multicolumn{2}{|r|}{ Projection } & \multicolumn{3}{|c|}{ Equal Angle } \\
\hline
\end{tabular}

Figure 5 Stereonet projections of the northwest wall

\section{$2.4 \quad$ Groundwater}

The majority of the groundwater in the FWQ is transferred through the major geologic structures due to the low hydraulic conductivity of the shale. The clay bands within the footwall shale are thought to have a low permeability essentially acting as a barrier for groundwater. During heavy rainfall, water seeps through the surface and is trapped between the clay bands and shale resulting in dilation along the bedding planes, increasing the pore pressure behind the wall leading to failure. Due to the significant amount of rainfall prior to the March (2019) failure (114 mm in 24 hours), the sump, pump and surface drainage was not able to sufficiently manage the water seepage into the FWQ wall and ultimately this led to the failure.

\section{$3 \quad$ Slope design}

The design criteria are based upon geotechnical investigations that were carried out by BFP Consultants (Campi et al. 2004) and supplemented by additional studies including the Phase 3 Expansion study (Fowler 2011) and West Wall Stability Review (Miller 2011) as well as onsite analysis and observations during excavation of the pit walls.

The inter-ramp slope angle (IRSA) in these studies refers to the wall angle in between haul ramp segments, ignoring the batter and berm geometries, which are able to be varied proportionally to other parameters, so long as the IRSA is achieved. Table 2 summarises the design parameters used on the northwest wall prior to experiencing multiple bench scale failures in these areas. 
Table 2 Design parameters in areas prior to multiple bench scale failure

\begin{tabular}{lcccccc}
\hline Failure date & $\begin{array}{c}\text { Failure } \\
\text { height }(\mathbf{m})\end{array}$ & $\begin{array}{c}\text { Failure } \\
\text { width }(\mathbf{m})\end{array}$ & $\begin{array}{c}\text { Failure } \\
\text { volume }\left(\mathbf{m}^{3}\right)\end{array}$ & $\begin{array}{c}\text { Bench } \\
\text { height }(\mathbf{m})\end{array}$ & $\begin{array}{c}\text { Berm } \\
\text { width }(\mathbf{m})\end{array}$ & $\begin{array}{c}\text { IRSA } \\
\text { (toe to toe) }\end{array}$ \\
\hline $27 / 01 / 2010$ & 56 & 30 & 2,400 & 16 & 10 & $46^{\circ}$ \\
$10 / 01 / 2014$ & 48 & 25 & 2,000 & 16 & 8 & $51^{\circ}$ \\
$22 / 12 / 2015$ & 111 & 160 & 355,000 & 16 & 8 & $51^{\circ}$ \\
$25 / 03 / 2019$ & 56 & 118 & 36,000 & $\begin{array}{c}8-16 \\
\text { transition }\end{array}$ & 10 & $31^{\circ}$ \\
\hline
\end{tabular}

IRSA - inter-ramp slope angle.

\section{$4 \quad$ Monitoring}

MRM uses various slope monitoring instrumentation to monitor and detect instabilities within and around the open cut pit. During the historic FWQ failures, radar and prism monitoring devices were used in parallel to monitor and detect instability on the western wall. Soon after the December 2015 failure, which forced closure of the slope access ramp, it was recommended for vibrating wire piezometers (VWP) to be installed behind the FWQ wall to monitor pore pressure before, during and after a rainfall event.

The most recent toppling failure indicated a direct correlation between the radar, prism and VWP data moments leading up to the failure.

\subsection{March 2019 failure monitoring observations}

\subsubsection{Radar monitoring}

Slope stability radars have been incorporated as a key critical monitoring system for mining within the FWQ. The slope stability radars enable real-time monitoring allowing for safe and efficient mining to progress. Implementing standard radar alarm thresholds is an effective method for early detection of wall movement enhancing the safety of mining activities in close proximity to instabilities. In addition, slope monitoring radar allows for the quantification of the development and progression of a failure to be captured which is essential to gain a better understanding of how slopes behave. The radar data captured during the failure is depicted in Figures 6 and 7. Initially, a significant rain event occurred at approximately 19:00 on the 24 March 2019 which corresponds to the preliminary signs of instability. MRM set four levels of alarm thresholds as required by the Trigger Action Response Plan (TARP). The radar alarm thresholds were activated shortly after the initial signs of instability with a Level 3 being activated at 19:00 followed by a Level 4 alarm being activated at 23:00. The failure occurred at 01:00 on the 25 March 2019. Having the radar thresholds set at the time of failure allowed for approximately two hours to evacuate personnel from the area (had they been working there) as per the instructions in the TARP. 


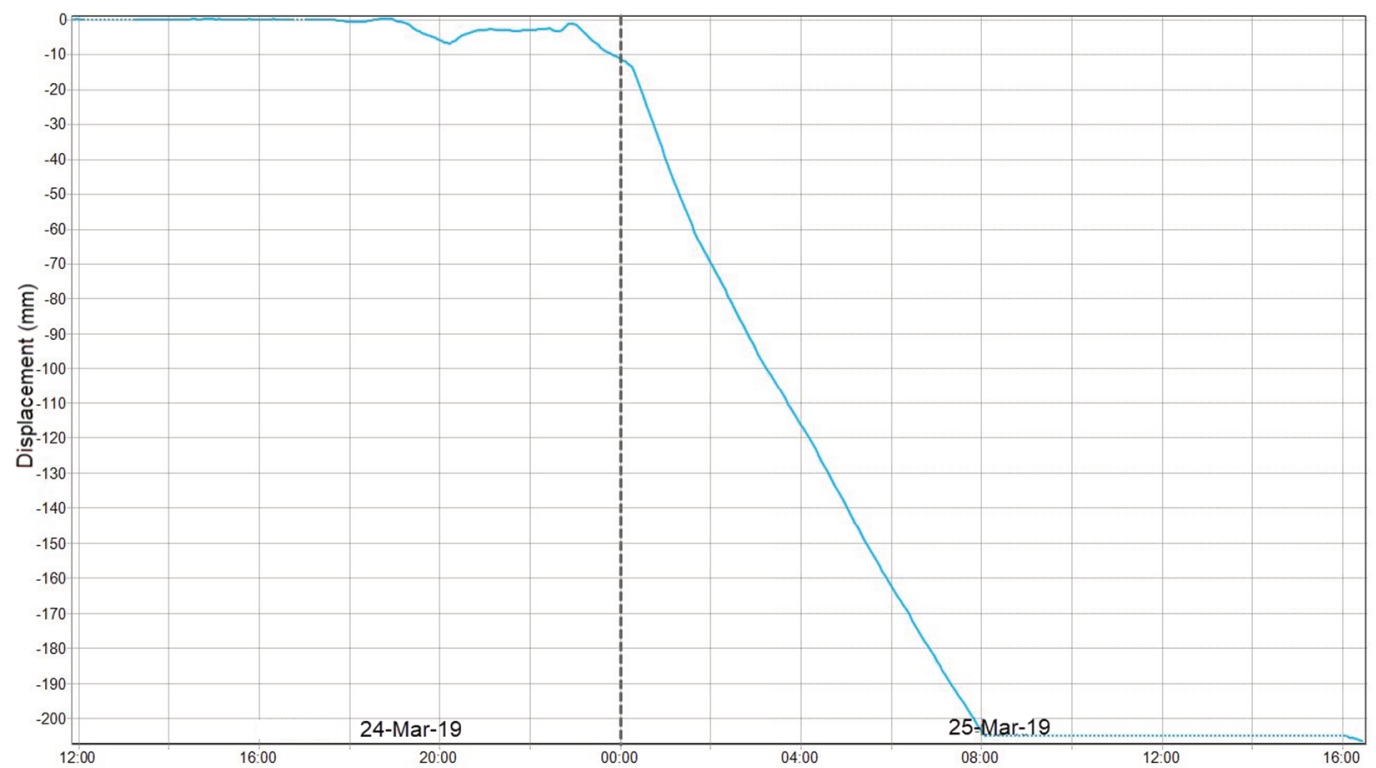

Figure 6 Displacement graph from IBIS radar showing events leading up to the failure

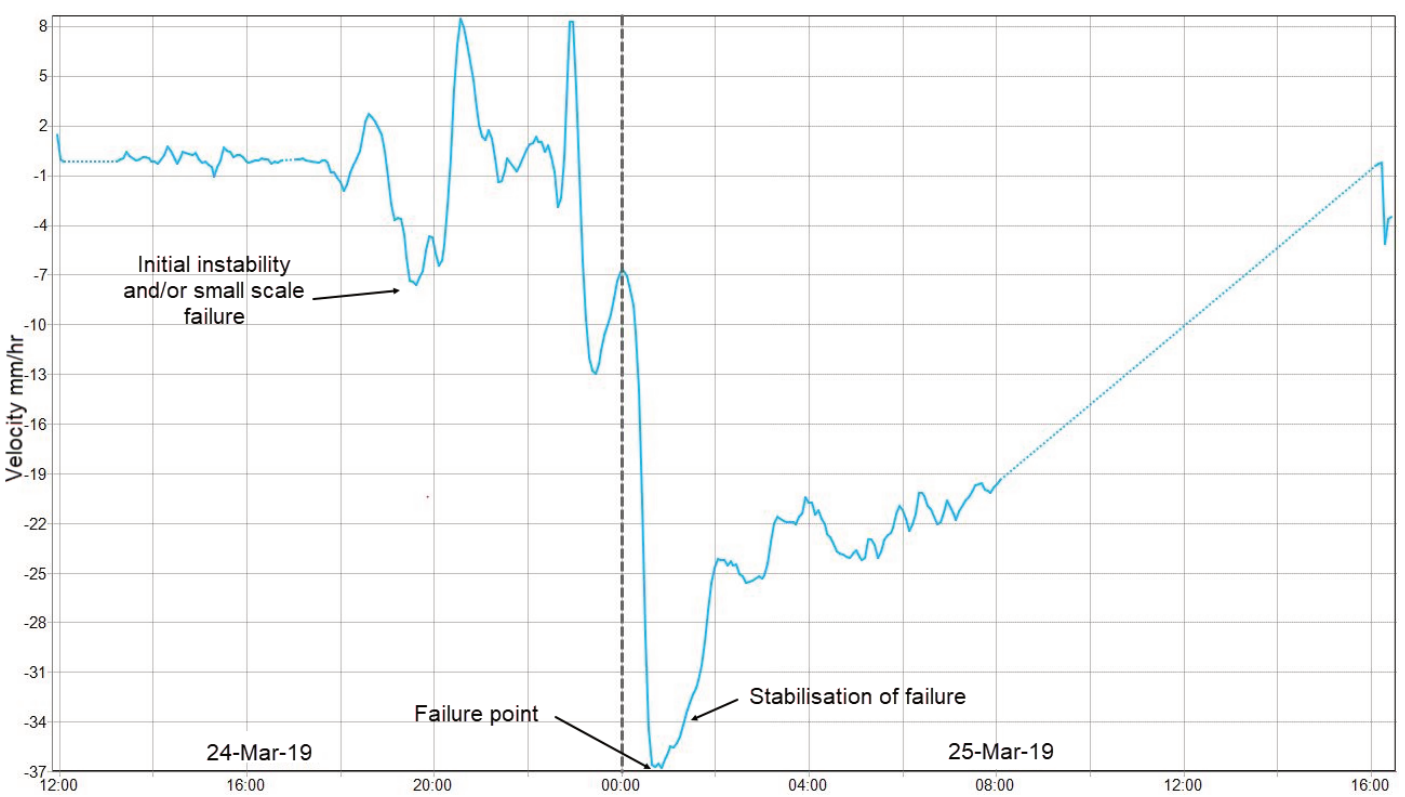

Figure $7 \quad$ Velocity graph from IBIS radar showing events leading up to the failure

\subsubsection{Prism monitoring}

Prism data has proven to be a reliable tool for monitoring long-term movement trends and cross-referencing of radar data. Ideal radar monitoring locations are often situated in active mining areas which require constant relocation of the equipment leading to gaps in acquired slope data and discontinuous slope behaviour trends over a longer time frame. Although there is software available to combine multiple radar data inputs to assist in analysis, prism monitoring continues to be a useful tool to provide a consistent continuous data trend to be utilised for analysis and validating radar data.

Prism data recorded in the FWQ in the year leading up to the failure, Figure 8 , shows there was continuous displacement on multiple prisms located near the failure zone. The movement is triggered in April 2018 and remains constant for most of 2018. Issues with total stations and the requirement to relocate the monitoring pillar as the result of a cut back in early 2019 resulted in large data gaps throughout the start of 2019. Data acquired during this period is relatively stable. No prism data is available during the failure as the total 
stations had been removed prior to Cyclone Trevor and had not yet been reinstalled. Upon reinstallation it was observed that multiple prisms were no longer reading as a result of being located in the failure zone.

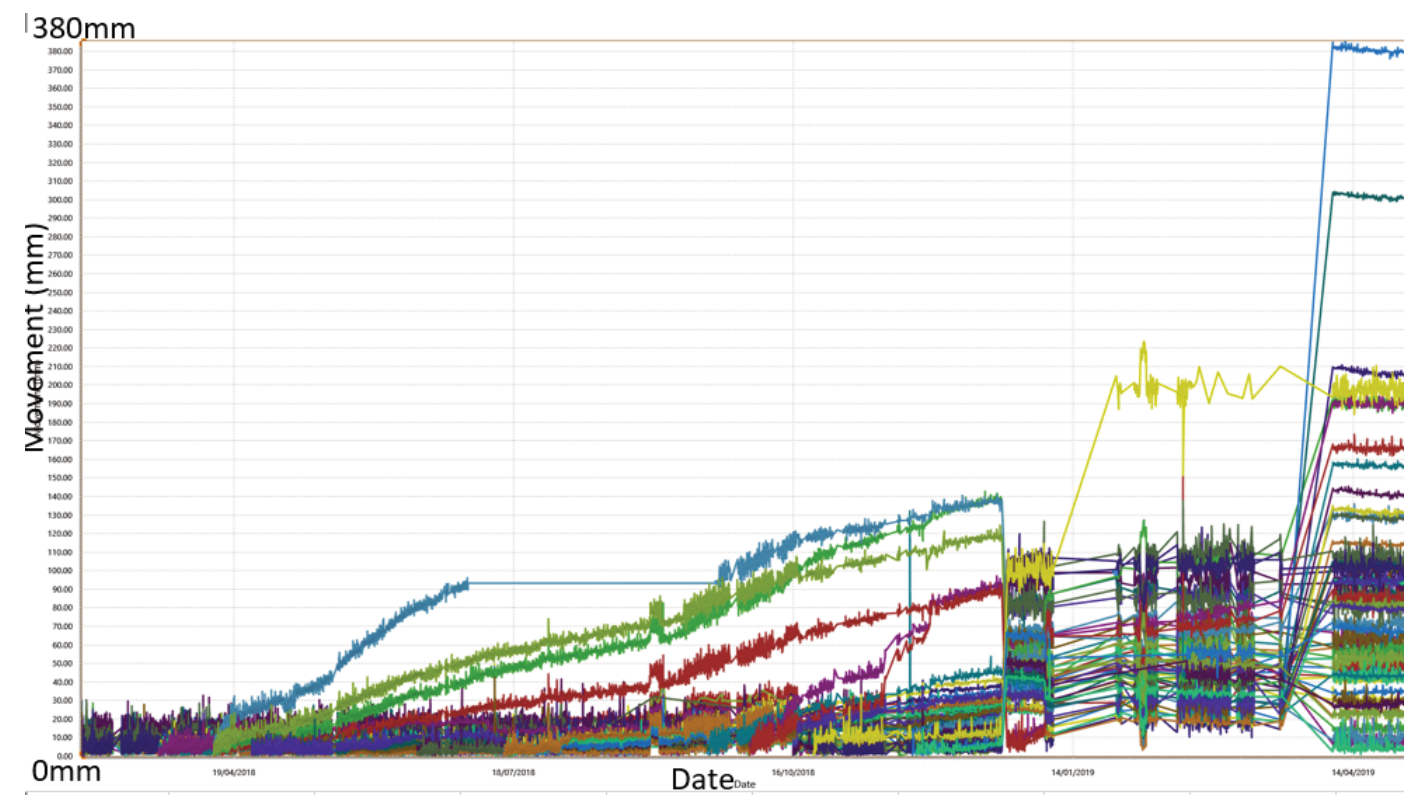

Figure 8 2D velocity graph of Footwall Quarry prisms from October 2018 to early March 2019

\subsubsection{Vibrating wire piezometer}

Groundwater pressure monitoring captured the response of the high intensity rainfall throughout the cyclone period. Prior to failure, an instrumented VWP hole was installed at an angle of $65^{\circ}$ towards the designed slope, a cross-section of the configuration is represented in Figure 9.

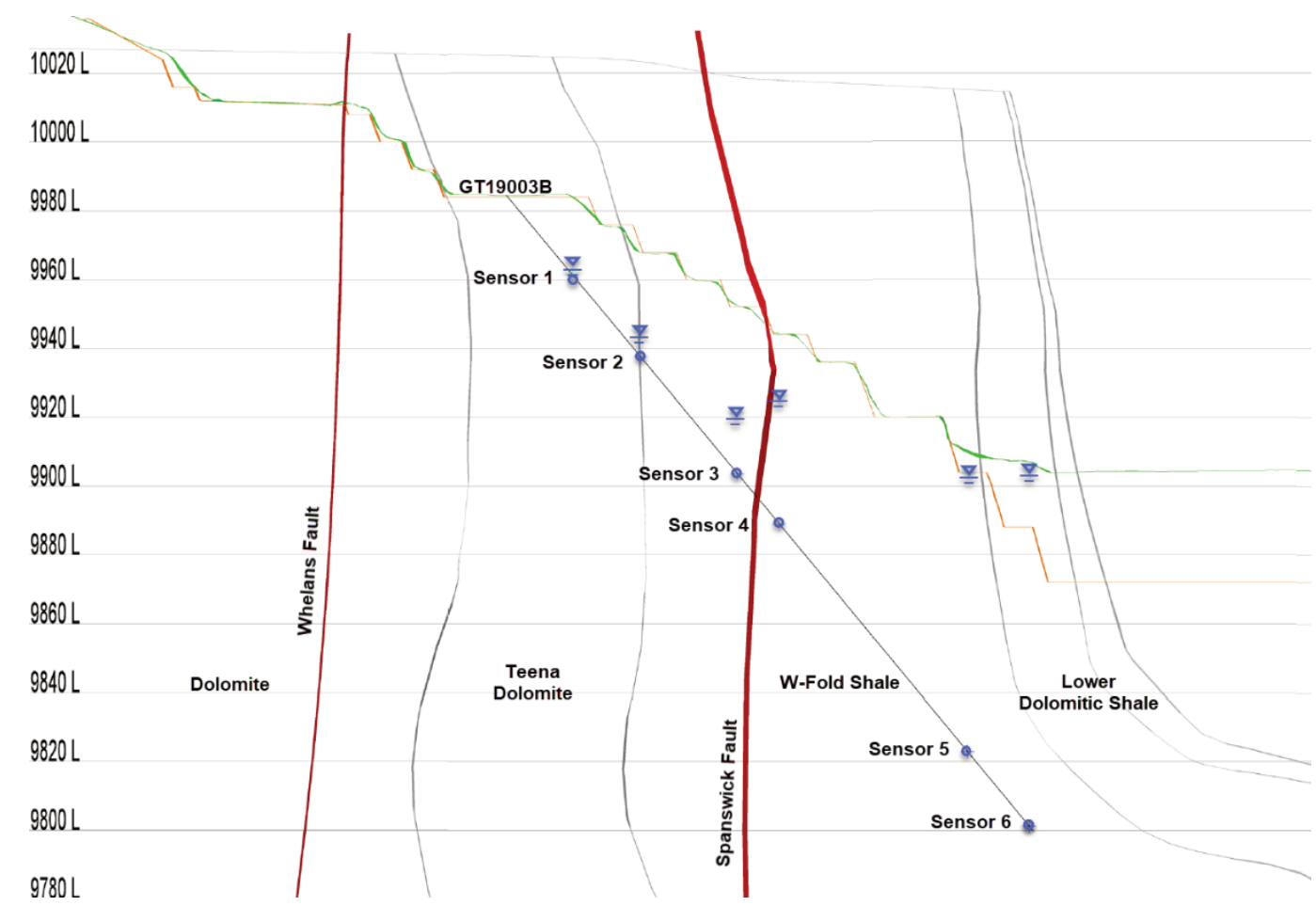

Figure 9 Cross-section of the vibrating wire piezometers installed prior to the failure indicating the pressure head achieved at the time of failure

The VWP data from the instrumented hole, as shown in Figure 9, indicate a distinct pressure spike during the major rainfall event. The increase in pore pressure was experienced by all VWP sensors, particularly sensor 4 
which already had elevated pore pressure due to the apparent interaction with the Spanswick Fault, shown in Figure 10. The VWP data indicate that hydro-mechanical coupling was occurring throughout the cyclone period, hence influencing the mechanical properties of the rock mass.

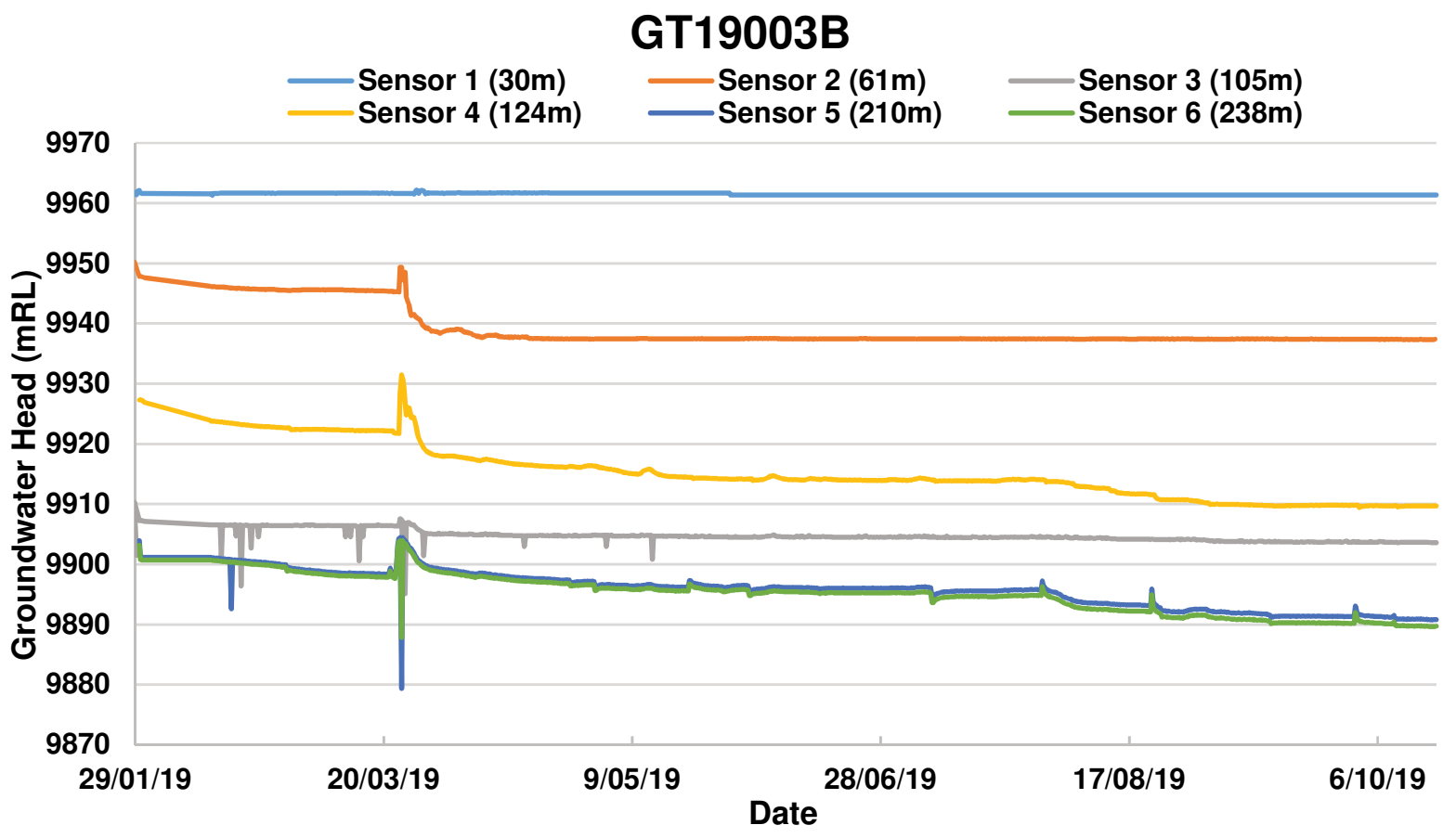

Figure 10 Vibrating wire piezometers (VWP) pressure head graph for VWP sensors located directly behind the failure

\subsubsection{Weekly photographs}

Drone footage taken before the failure showed no signs of instability along the southwestern FWQ wall. An inspection was conducted the morning of the failure and revealed dilation of bedding towards the northwestern FWQ wall and new cracks along the south in situ berm. Weekly photographs captured since the failure showed the failure outline extending into the in situ wall with fresh cracks running perpendicular to the bedding along the northwestern wall.

\subsection{Post-failure observations}

\subsubsection{Radar monitoring}

Radar monitoring and applicable alarm thresholds have been vital for the continued safe and efficient mine production. The radar alarm thresholds at MRM have been re-assessed and modified following every failure event to better depict the behaviour of the slope. Since the initial failure was observed in March 2019, movement of the slope had continued with failure of the lower benches and lateral extension of the failed zone occurring, as displayed in Figure 11. Due to the continued extension of the failure, radar threshold alarms were set as shown in Table 3. The failure velocities achieved between the in situ wall and post-failure rill are significantly different which has been taken into consideration when setting the radar alarm thresholds. The comparison of the failures shows a failure lower velocity rate prior to failure for in situ rock mass (approximately $7 \mathrm{~mm} / \mathrm{hr}$ ) compared to post-failure rill (approximately $30 \mathrm{~mm} / \mathrm{hr}$ ). It should be noted that the movement rates are site based and reflect the specific geology and historic behaviour of the FWQ wall. 


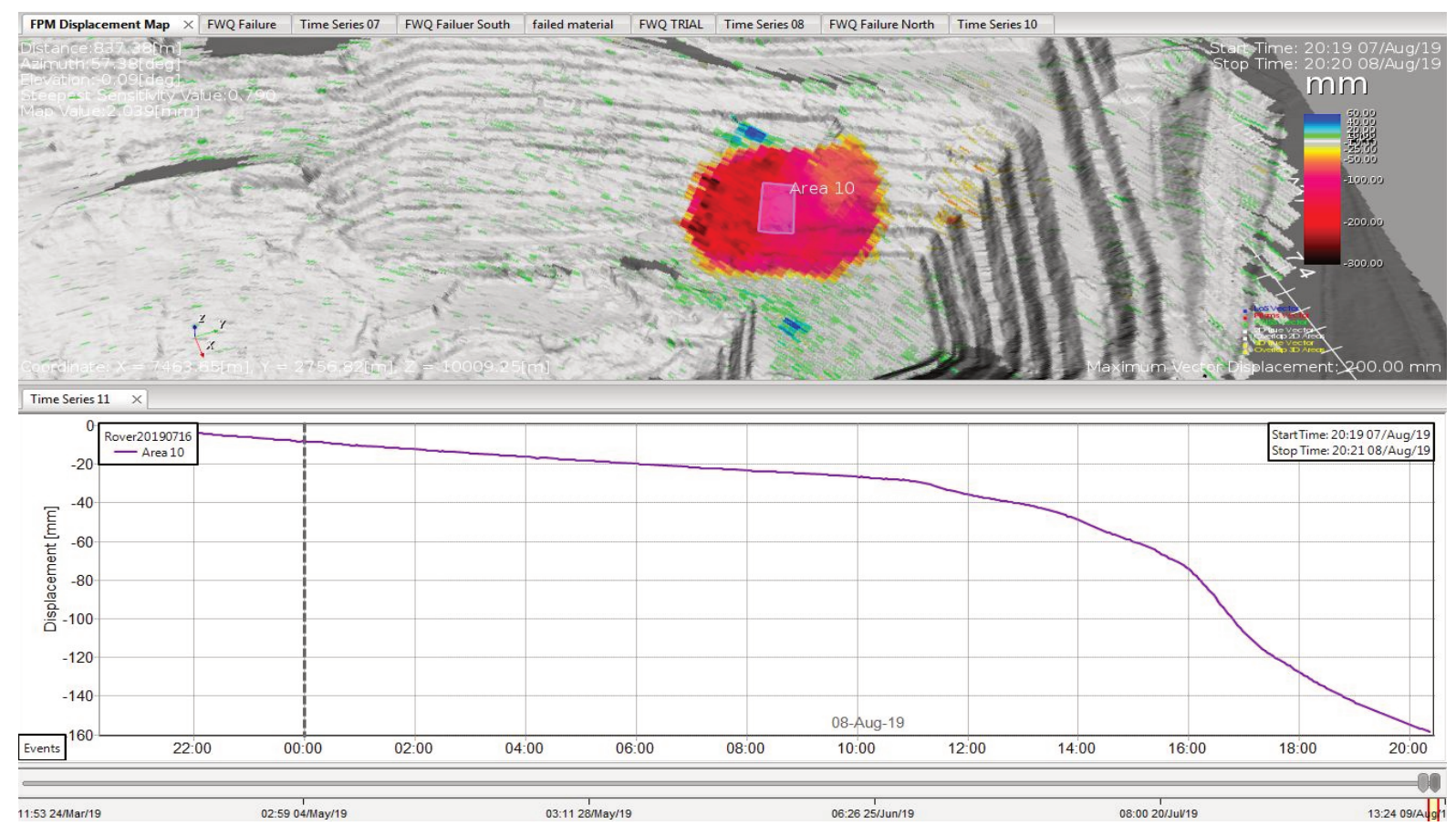

Figure 11 Displacement graph from IBIS radar showing events throughout the remediation of the March 2019 failure

Table 3 MRM radar alarm thresholds and response action

\begin{tabular}{llll}
\hline Notified work group & $\begin{array}{l}\text { Threshold value } \\
\text { (in situ) }\end{array}$ & $\begin{array}{l}\text { Threshold value } \\
\text { (failed material) }\end{array}$ & Action \\
\hline $\begin{array}{l}\text { Geotechnical department } \\
\text { All mining operations and } \\
\text { geotechnical department }\end{array}$ & $7 \mathrm{~mm} / \mathrm{hr}$ & $10 \mathrm{~mm} / \mathrm{hr}$ & $\begin{array}{l}\text { Investigate and inspect } \\
\text { Prepare for evacuation }\end{array}$ \\
$\begin{array}{l}\text { All mining personnel and } \\
\text { mine manager }\end{array}$ & $10 \mathrm{~mm} / \mathrm{hr}$ & $30 \mathrm{~mm} / \mathrm{hr}$ & Evacuate area immediately \\
\hline
\end{tabular}

\subsubsection{Prism monitoring}

Figure 12 shows prism monitoring in the FWQ from March 2019 onwards. There is currently no significant movement or acceleration being recorded through prism monitoring in this area. Although there is no movement being recorded it should be noted that multiple prisms were lost during the March 2019 failure, and as a result there is currently no prism coverage in areas of movement being recorded by the slope stability radars. 


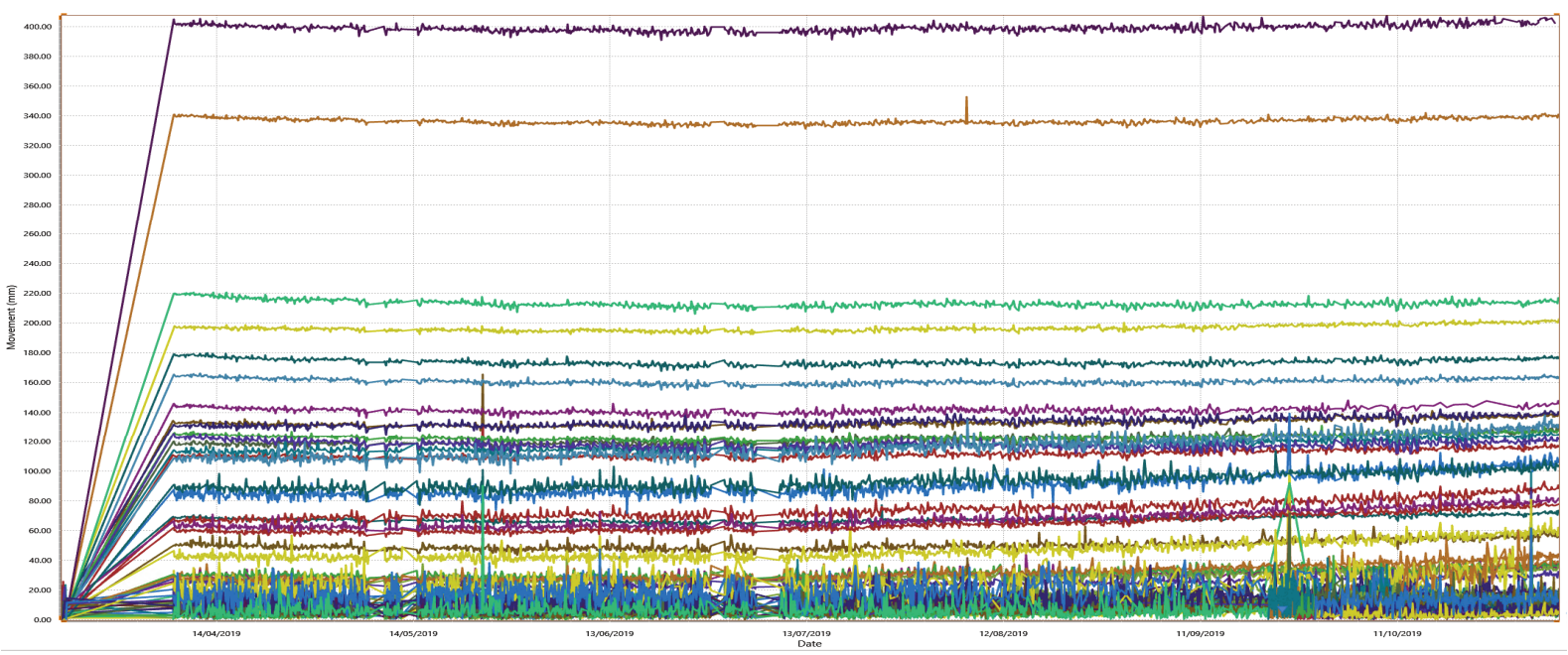

Figure 12 Prism movement on the west wall following March 2019 failure

\subsubsection{Vibrating wire piezometers}

A slope depressurisation program is currently being coordinated to assist with FWQ wall depressurisation, aiming to reduce the phreatic surface in this area. In conjunction with this drilling program, VWPs will be installed in two holes to assist in gaining a better understanding of the proximity of the phreatic surface in conjunction with pit slope. Currently the depressurisation drilling has displayed positive results, assisting to depressurise the slope. Drilling will be completed prior to the 2019 wet season and results monitored throughout the season.

\section{$5 \quad$ Analysis and management}

\subsection{Failure mechanism}

It is believed that 2019 FWQ failure was initiated from the toe of the failure one bench above the active mining area on the 9,920 metre reference level (mRL) triggering a flexural toppling failure. The bedding orientation of the western wall dips into the slope which is not typical for a toppling failure, typical toppling failure mechanism shown in Figure 13. The toppling mechanism for the western wall is believed to initiate due to the swelling of the clay infills coupled with water ingress with external forces on the bedding wall causing the beds to rotate as shown in Figure 14.

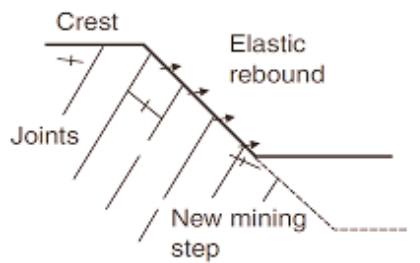

IV

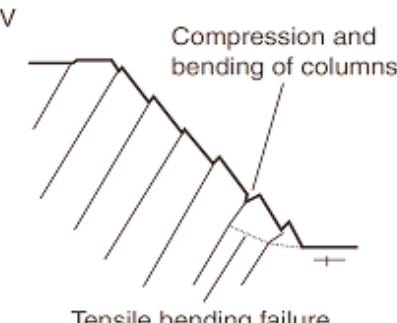

Tensile bending failure at base of rotation

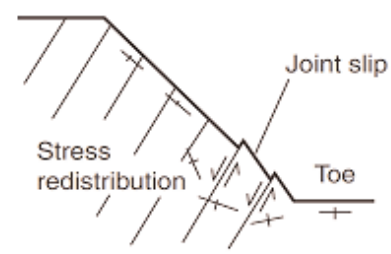

V

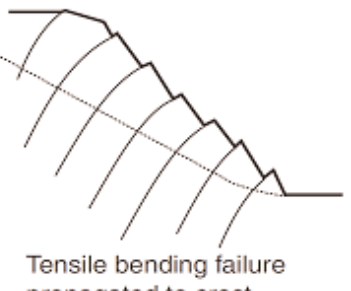

propaqated to crest
III

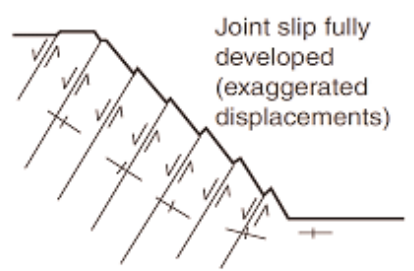

VI

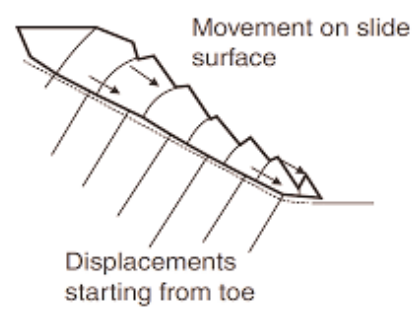

Figure 13 Cross-section showing development of a toppling failure (Read \& Stacey 2009) 


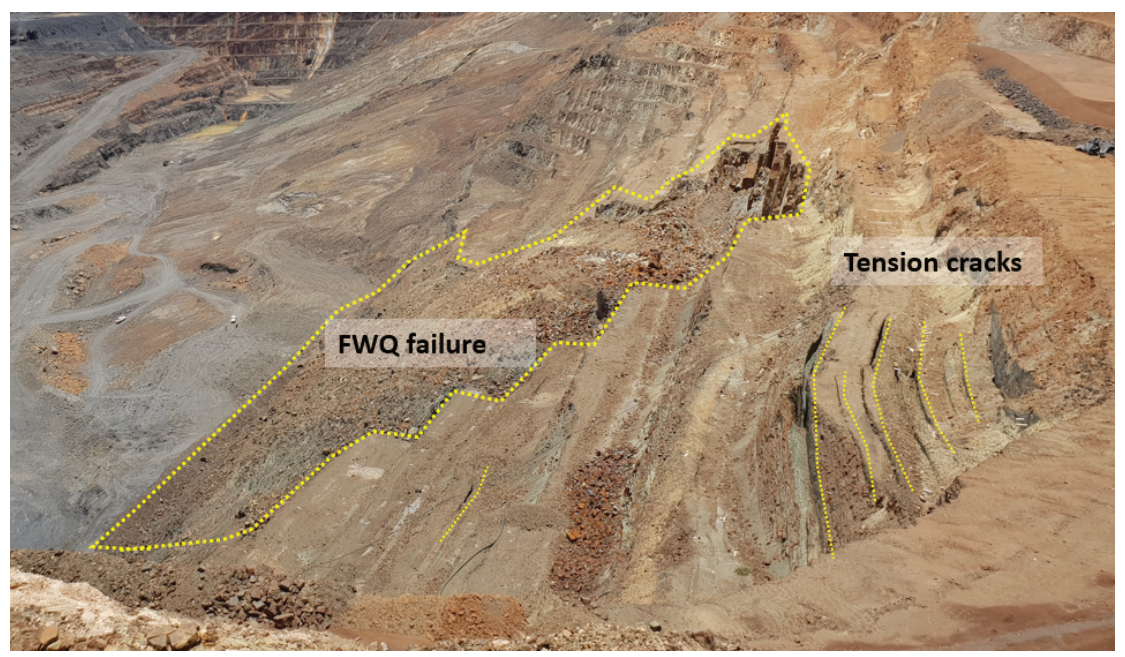

Figure 14 Photo of the western wall highlighting the rotation of the sub-vertical bedding due to water ingress and swelling of the tuffaceous bands

Onsite interpretation determined the failure initiated on the northern half of the FWQ wall where there was a change in batter height from $8 \mathrm{~m}$ to $16 \mathrm{~m}$ in an area with weaker rock mass, batter height highlighted in Figure 15. As-built berms along the south may have acted as a buttress preventing the failure mass from extending south within slightly better rock mass.

Key findings:

- The orientation of bedding being parallel to the bench face, weak rock mass type and the addition of significant water induces a toppling failure in the FWQ.

- Design of $8 \mathrm{~m}$ bench height and $7 \mathrm{~m}$ berm have proven to increase stability of the FWQ walls. The March 2019 failure initiated on a $16 \mathrm{~m}$ batter with no berm mid-bench. Although the southwest FWQ wall had been flooded with surface runoff, the wall did not fail due to low bench height $(8 \mathrm{~m})$ and the existence of a berm (potentially acting as a buttress).

- Alarm thresholds vary between in situ rock and failed mass, having the appropriate thresholds in the correct rock type assists in wall monitoring to maximise production and reduce delays.

- Surface drainage and depressurisation of slope are essential, especially in conjunction with weaker material types.

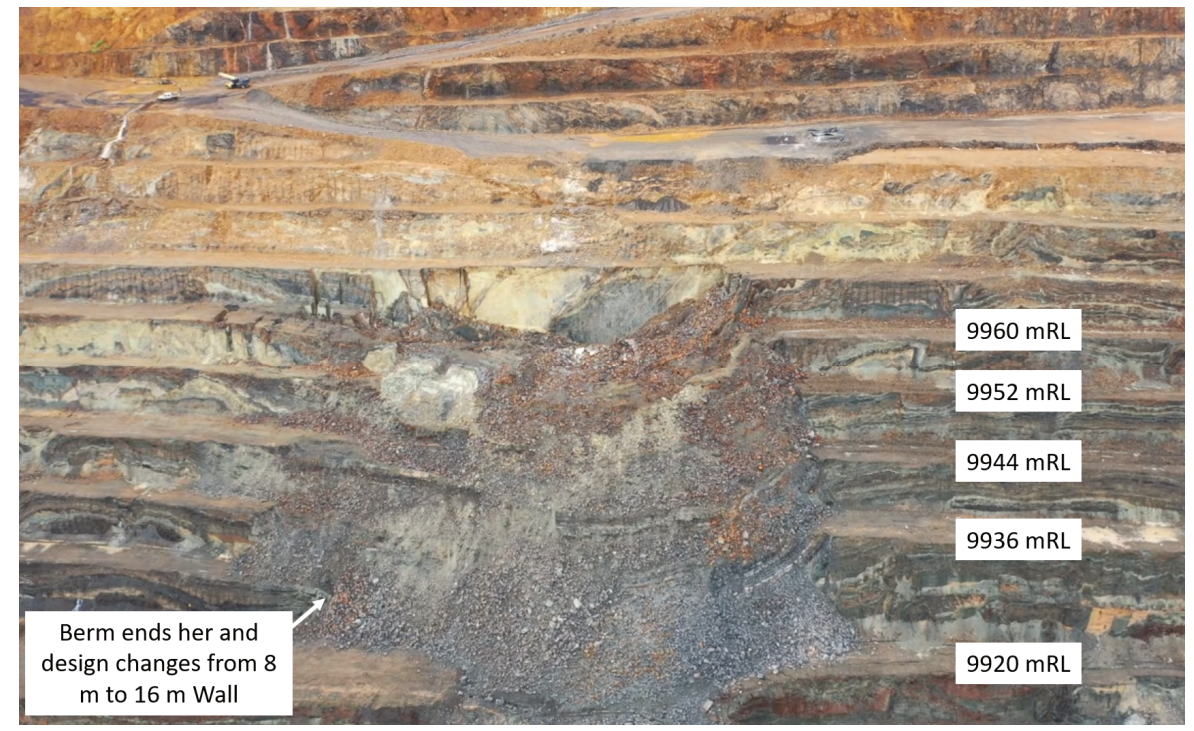

Figure 15 Photo taken of the Footwall Quarry failure on 25 March 2014 


\section{Remediation works and ongoing failure management}

Given the significant high-grade ore reserves below the failed material, remediation options were developed to facilitate the safe recovery of ore. Four remediation options were presented to Mine Management to determine the best way to progress mining below the failure zone.

1. No remediation of the failed material and a standoff on the eastern extent of the failed material. This option would be the lowest risk however would sterilise significant quantities of high-grade ore.

2. Partially mine out slip debris from the east and manage rockfall hazard on working levels of the pit floor. This option would ensure current pit design is achieved, however significantly increasing the rockfall hazard from loose material above the working area.

3. Utilising a 'mine and manage' approach where a combination of stand-offs and significant geotechnical monitoring are used to ensure that, while not compromising safety, the most aggressive design possible can be achieved. This option would include some ore sterilisation.

4. Mine out a cutback behind the failure to completely remediate the failed area. This option would ensure no ore sterilisation but would incur significant time delays.

Ultimately, Option 3 was selected as the preferred method.

\subsection{Mine and manage approach}

A geotechnical exclusion zone (GEZ) was established $50 \mathrm{~m}$ from the toe of the failed mass to limit exposure of personnel to the higher risk work area. A risk assessment was completed to determine adequate controls are in place prior to personnel entering and working in the GEZ. These controls included active radar and prism monitoring without stability alarms triggered, day shift work only and no work during or immediately following rainfall or blast events. The GEZ was defined using a combination of Rocscience modelling tools and field observations to determine potential maximum run out distances of any future falls of ground.

Initially work was completed by Operations to remove material from the toe of the failure, this was successful in reducing the volume of failed material on the wall. However, the result left a $50 \mathrm{~m}$ high rill slope with the top $34 \mathrm{~m}$ angled at $34^{\circ}$ and the lower $16 \mathrm{~m}$ steepened to $48^{\circ}$. A cross-section of the failure highlighting angles is presented in Figure 16.

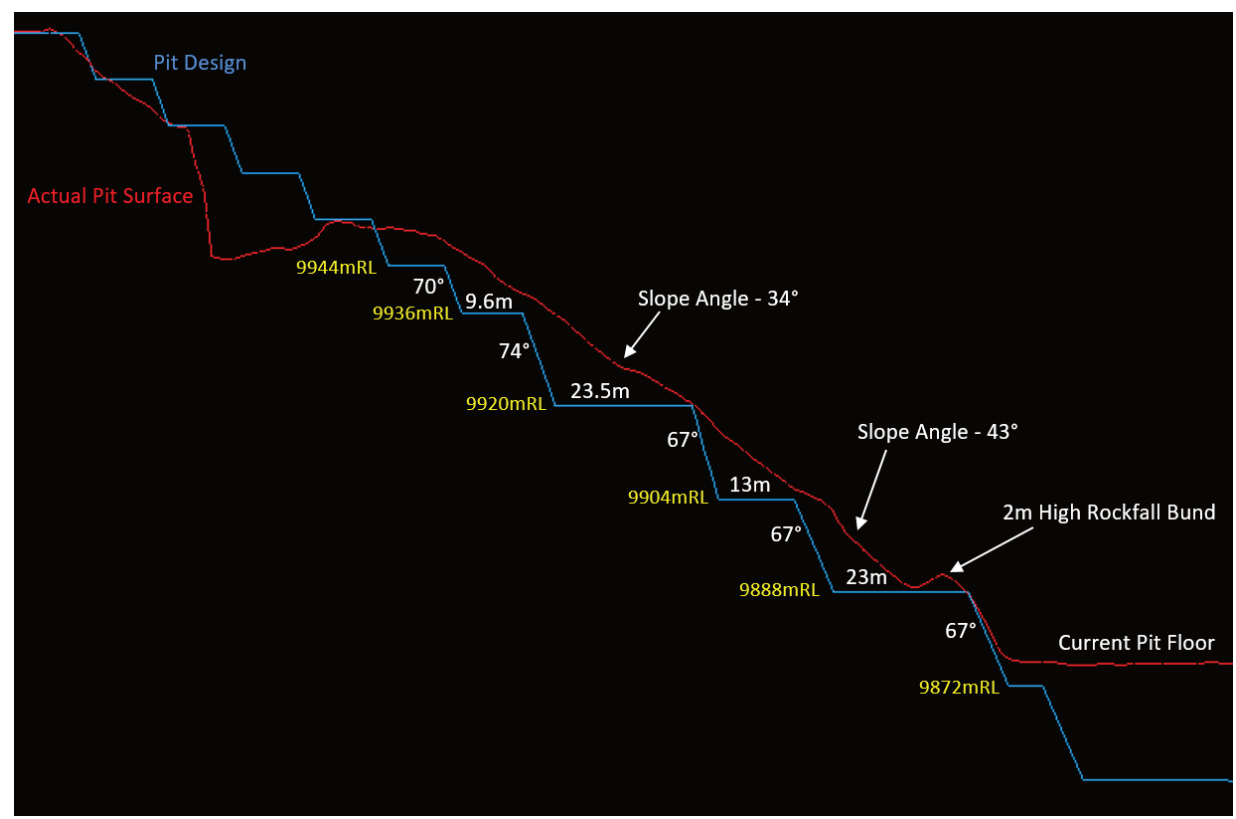

Figure 16 Cross-section comparing current pit surface to pit design (cross-section through middle of failure zone) 
A step-out was designed with the berm below the failure being extended from the $8.5 \mathrm{~m}$ design to $13 \mathrm{~m}$. This change in design left room on the berm to install a $1.5 \mathrm{~m}$ high catch bund to assist in reducing rockfall risk to personnel working below the failure. This approach was successful and enabled production to continue safely on the 9,904 mRL. Since firing and excavating the next shot, the slope has continued to settle, filling up the catch bund resulting in the failed material sitting at a continuous angle of $34.5^{\circ}$.

Mining progressed through the next $16 \mathrm{~m}$ bench with a GEZ in place up to $35 \mathrm{~m}$ from the toe of the west wall. Pre-split drilling was utilised on the west wall to best try and achieve the design; however, as the wall was exposed, it was discovered that the $16 \mathrm{~m}$ bench between 9,904 mRL and 9,888 mRL was highly fractured. Mining through this bench triggered multiple radar alarms that resulted in evacuation from the FWQ mining area while the wall settled back to a non-alarming state causing multiple production delays that varied between an hour and multiple days. Movement was predominantly observed on the failed material but at times extended into the in situ rock mass surrounding the failure zone.

A decision was made by management to try and reduce production delays as a result of wall movement, to enable better ore returns prior to wet season. In order to achieve this directive, a $23 \mathrm{~m}$ wide berm was designed with a $2 \mathrm{~m}$ high catch bund positioned $1 \mathrm{~m}$ back from the crest of the berm. The berm width was determined by combining the location of a change in lithology with the projected slope run out distance (if it was to settle to the $37^{\circ}$ angle of repose).

Mining is currently being conducted between $9,888 \mathrm{mRL}$ and $9,872 \mathrm{mRL}$. The GEZ has been reduced to $10 \mathrm{~m}$ from the designed toe and movement of the failed material has yet to be triggered as a result of mining in this area. The exposed batter is predominantly in situ material with bedding parallel to the bench face.

Despite the high-risk nature of the work conducted in remediating and continuing to mine below the failure using a mine and manage approach, all risks associated with the project were managed successfully and without incident.

\section{$7 \quad$ Future works}

A slope depressurisation program is currently being coordinated to assist with depressurising the west wall of MRM. Depressurisation holes will be drilled in arrays located to both the north and south of the failed wall with hole depths ranging from $75 \mathrm{~m}$ to $150 \mathrm{~m}$. The aim is to intersect changes in lithology and major geologic structures behind the failure plane. To gain a better understanding of the pore pressures in the west wall and how this is affected during the 2019/2020 wet season, VWPs will be installed in two drillholes. Work will be completed on this project prior to the coming wet season.

A slope design update has been developed and will be carried out by the MRM Geotechnical Department in conjunction with Pells Sullivan Meynink (PSM) to update the Geotechnical Study of the MRM Open Pit conducted by BFP Consultants in 2004. The update aims to collate all relevant site data and utilise this to create updated structural, rock mass and groundwater models for the entire pit. These models will then be utilised to perform analysis and provide recommendations for all areas of geotechnical concern.

\section{Conclusion}

This paper presents a large-scale toppling failure of the MRM west wall. There have been five similar events on two successive cutbacks. Slope heights range from 48-112 m, predominantly with $16 \mathrm{~m}$ bench height and IRSA ranging between $34^{\circ}$ and $51^{\circ}$.

The key factors controlling the instability are:

- Weak steeply dipping interbedded W-Fold Shale rock mass.

- Flexural toppling mechanism.

- High pore pressures.

- Additional transient loading from large seasonal rainfall events. 
Operationally the instabilities have caused delays to mining, both from the cessation of mining beneath the failure as a result of slope stability alarms being triggered, and to a lesser degree the clean-up of the failed mass. A number of step-outs have been used to manage the failure as mining has progressed.

Management of the unstable slopes has been successful, employing essentially three components: site procedures, walk-over inspections and a geotechnical monitoring program comprising prism, radar and VWP monitoring systems. A trend has been identified at MRM where the onset of slope instability occurs some six months prior to collapse, and the collapse phase is triggered by rainfall within a day or days of the event.

At present, stabilisation projects have commenced which include the depressurisation of the FWQ wall through a horizontal drain program and a slope design update.

\section{Acknowledgement}

The authors acknowledge Glencore's McArthur River Mine for permission to publish this paper, The McArthur River Mine Geotechnical Department and both Mark Fowler (PSM) and Geoff Beale (Piteau Associates) for their ongoing support and assistance.

\section{References}

Campi, B, Dugan, KJ \& Coulthard, M 2004, Geotechnical Study of the McArthur River Mine Open Pit, BFP Consultants Pty Ltd, Melbourne.

Fowler, M 2011, McArthur River Mine Expansion Phase 3 Feasibility Study - Structural Analysis, Pells Sullivan Meynink, Sydney. Miller, D 2011, West Wall Slope Stability Review, Coffey Mining, Notting Hill.

Read, J. \& Stacey, P 2009, Guidelines for Open Pit Slope Design, CSIRO Publishing, Collingwood. 
